\title{
Sources of avoidance motivation: Valence effects from physical effort and mental rotation
}

\author{
Ezequiel Morsella $\cdot$ Giles H. Feinberg • \\ Sepeedeh Cigarchi · James W. Newton · \\ Lawrence E. Williams
}

Published online: 4 June 2010

(C) The Author(s) 2010. This article is published with open access at Springerlink.com

\begin{abstract}
When reaching goals, organisms must simultaneously meet the overarching goal of conserving energy. According to the law of least effort, organisms will select the means associated with the least effort. The mechanisms underlying this bias remain unknown. One hypothesis is that organisms come to avoid situations associated with unnecessary effort by generating a negative valence toward the stimuli associated with such situations. Accordingly, merely using a dysfunctional, 'slow' computer mouse causes participants to dislike ambient neutral images (Study 1). In Study 2, nonsense shapes were liked less when associated with effortful processing $\left(135^{\circ}\right.$ of mental rotation) versus easier processing ( $45^{\circ}$ of rotation). Complementing 'fluency' effects found in perceptuo-semantic research, valence emerged from action-related processing in a principled fashion. The findings imply that negative valence associations may underlie avoidance motivations, and have practical implications for educational/workplace contexts in which effort and positive affect are conducive to success.
\end{abstract}

Keywords Processing fluency - Effort .

Law of least effort - Valence

E. Morsella $(\bowtie) \cdot$ G. H. Feinberg · S. Cigarchi · J. W. Newton Department of Psychology, San Francisco State University (SFSU), 1600 Holloway Avenue, EP 301, San Francisco, CA 94132-4168, USA

e-mail: morsella@sfsu.edu

E. Morsella

Department of Neurology, University of California,

San Francisco, San Francisco, CA, USA

L. E. Williams

Leeds School of Business, University of Colorado, Boulder, CO, USA

\section{Introduction}

When reaching goals by acting upon the world, organisms must simultaneously strive to meet the overarching goal of conserving energy. It would be detrimental for organisms to expend energy indiscriminately, either for physical actions such as moving and negotiating objects or mental actions such as solving puzzles, sustaining attention, or mentally rotating objects in one's mind. According to the law of least effort (or 'work'; Botvinick 2007; Hull 1943), faced with several ways to reach the same end, an organism will select the means associated with the least expenditure of effort. The actual mechanisms giving rise to this strong and most basic of human biases remain unknown. One possibility is that we explicitly assess how much effort is associated with each means of reaching a goal and then select the one associated with the least amount of effort. Such an algorithm for selecting the path of least resistance would be computationally challenging, potentially requiring episodic memory and simulations of actions and their consequences (Arkin 1998; Schacter and Addis 2007). Alternatively, it has been hypothesized that an organism comes to avoid situations associated with the expenditure of effort in a more reflexive manner-by automatically generating a negative valence toward the stimuli associated with such situations (Botvinick 2007; Hull 1943; Lewin 1935). This valence from effort hypothesis addresses a basic aspect of the human condition, one that predicts and explains action selection across a wide variety of contexts. The hypothesis predicts both conscious and unconscious (Bargh and Morsella 2008; Morsella and Bargh in press) preferences toward cognitive and behavioral tasks featuring little effort, over those tasks that are needlessly effortful. Accordingly, in everyday life, it seems that one does avoid objects and situations associated with excess 
effort, such as the shopping cart with the bad wheel, the slow computer that always crashes, and contexts in which one must perform effortful mental transformations (e.g., unnecessarily translating between languages). But do the preferences in these anecdotes really indicate that one generates a negative valence toward stimuli associated with effortful overt action (e.g., physical movement) and covert action (e.g., rotating mental imagery)? For instance, does pushing the cart with the bad wheel increase one's dislike for the store products that happen to fall upon the eye?

Some research hints that the answer is yes. For example, in perception research, it has been shown that processing generates positive affect when it is smooth and facile, as during the processing of visual stimuli that are familiar, prototypical, or easy to perceive (e.g., high figure-ground contrast; Jacoby et al. 1989; Winkielman et al. 2003). Such effects of processing fluency have been found in domains outside of vision (Alter and Oppenheimer 2006; Garbarino and Edell 1997; Jacoby et al. 1989; Janiszewski and Meyvis 2001; Luce 1998; Luce et al. 1997; Oppenheimer 2006, 2008; Reber et al. 1998; Schwarz 2004) (For a thorough review of processing fluency effects, see Alter and Oppenheimer 2009). For instance, research on consumer behavior has revealed valence effects from the effortful processing associated with challenging language or brand names (Alter and Oppenheimer 2006; Garbarino and Edell 1997; Luce 1998; Luce et al. 1997; Oppenheimer 2006; Schwarz 2004). In general, positive affect and more liking are associated with fluent, or less effortful, processing.

Importantly, most research has documented valence effects from the effort associated with the input, stimulusend of processing; much less is known about valence effects from effort associated more with the output, action-end of processing (Morsella 2009; Rosenbaum 2005), stages of processing proposed to be associated with the highest levels of subjective effort (Morsella et al. 2009b; Sanders 1983). Regarding these stages of processing, the theoretical perspectives and empirical evidence are mixed. On one hand, it has been shown that people prefer situations and stimuli that require little response interference/conflict (Higgins 2005; Rosen et al. 2007; Winkielman et al. 2003). For example, Beilock and Holt (2007) showed that skilled typists prefer letter strings that, when typed using standard typing methods, engender little or no motor interference (e.g., the visual stimulus $F J$ would be preferred over $F V$ ). Typists were unaware of the motoric-based reason for their preference. Moreover, Fenske and Raymond (2006) have demonstrated that visual stimuli (e.g., abstract patterns) can acquire a negative valence if they must be ignored or suppressed, which involves cognitive effort. Thus, regarding the response-end of processing, positive affect and more liking appear to be generally associated with fluent, or less effortful, processing.
On the other hand, a wealth of research supports a view that difficult (but not excessively difficult) goal pursuit enhances the desirability of end-states (Brehm and Self 1989; Brehm et al. 1983; Wright 1996). In this research tradition on motivational intensity and energization, it is consistently found that when the actions needed to accomplish a goal are challenging (versus easy or impossibly difficult), the goal is more desirable (Friedman et al. 1968), suggesting that effortful action is motivating and generates positive valence. Similarly, hungry participants found a sandwich to be more attractive when success at an effortful (versus easy) cognitive task was necessary to obtain it (Biner et al. 1991). At first glance, these effects appear at odds with the fluency literature, in which effortful processing is associated with negative affect, decreased liking, and lowered evaluations of difficult-to-process information (cf. Alter and Oppenheimer 2006). See "General discussion" for a treatment of how these two lines of research may be accurately describing different aspects of the same process of goal-pursuit.

Given the ambiguity in the literature, empirical evidence is needed to verify the notion that effortful overt and covert actions automatically generate a negative valence that can then influence liking toward ambient stimuli. It is important to note that the aforementioned valence effects in the literature stem from phenomena that are fundamentally different in nature from the kinds of quotidian, brute exertions of effort mentioned above (e.g., pushing a shopping cart with a faulty wheel). For example, valence data from response interference may reflect more than just the effects of mental effort, as it is well known that response interference tasks also include activation of a host of executive processes and the suppression of often pre-potent action plans (Cohen et al. 1990; DeSoto et al. 2001; MacLeod and McDonald 2000). Thus, one question that remains unanswered is whether brute effort alone, covarying with stages of processing related to the execution of physical or covert actions (e.g., manipulating an object physically or mentally), generates a negative valence toward the ambient stimuli associated with those actions. If so, this would support a view that the negative affect generated by effort is one of the sources of avoidance motivation.

To address this gap in the literature, in Study 1 we examined whether the effort required to move an object can generate a negative valence toward an ambient visual stimulus. Specifically, we evaluated whether moving an object displayed on the computer screen with a 'slow' computer mouse generates a negative valence toward an ambient figure presented on the same screen. This task captures key features of our shopping cart example. This basic finding would contribute to the literatures on motivation and goal pursuit (Gollwitzer et al. 2009; Higgins 1987; Kruglanski and Kopetz 2009; Lewin 1935) and on 
valence effects from processing dynamics, and would be the first demonstration of valence effects from effort at the level of action implementation, in a situation capturing the features of the everyday examples mentioned above. In Study 2, we extended our investigation by examining not the effects of moving an object physically, but the effects stemming from manipulating and negotiating an object mentally. In this study, we examined the valence effects stemming from the act of mental rotation. In one condition, the object could be rotated mentally with little mental effort; in another condition, the mental rotation demanded more effort. We predicted that, based on the hypothesis of valence from effort, the second condition would lead to less liking of the objects. This study builds on previous research (e.g., Morsella et al. 2009b) and theories (Bargh and Morsella 2008; Vygotsky 1962) suggesting that covert actions have the same subjective properties as overt actions. Taken together, these investigations demonstrate that features of situations involving the unnecessary expenditure of effort acquire a negative valence, an effect that may be a source of avoidance motivations.

\section{Study 1}

Overview and rationale

Using a computer mouse, participants were instructed to 'drag' the image of a square diagonally from the top left corner of the computer screen to the bottom right corner, much in the way that one manipulates the icons on a desktop computer. For half of the session, the computer mouse performed normally (the Easy condition); during the other half of the session, the mouse became a 'slow' mouse (the Effortful condition), which demanded more correcting and jerking actions from the participant. On each trial, following the dragging action, participants were asked to rate how much they liked a nonsense figure that was presented on the screen. According to the valence from effort hypothesis, the exertion of effort at the level of action implementation should generate a negative valence that then influences likeability of the figure. Hence, we predicted that valence would spill over onto this figure, making participants prefer (i.e., like) ambient shapes in the Effortful condition less than shapes in the Easy condition.

\section{Method}

\section{Participants}

San Francisco State University undergraduates $(n=47)$ participated in a within-subjects design for course credit. For reasons explained below, the data from three participants were excluded from analysis.

\section{Procedures}

By interacting with items on the computer desktop in much the same manner that one drags file icons from one desktop location to another (e.g., from the desktop into a folder), participants manipulated (or 'dragged') an image on the computer screen with either a normal (Easy condition, a block of 32 trials) or slow (Effortful condition; 32 trials) computer mouse. After this act, they rated how much they liked the nonsense figure that happened to be presented on the screen (see example in Fig. 1b). At the beginning of

Fig. 1 Sample screen environment at the beginning of a trial (a) and toward the end of the same trial (b), after the image of the square had been dragged diagonally across the screen

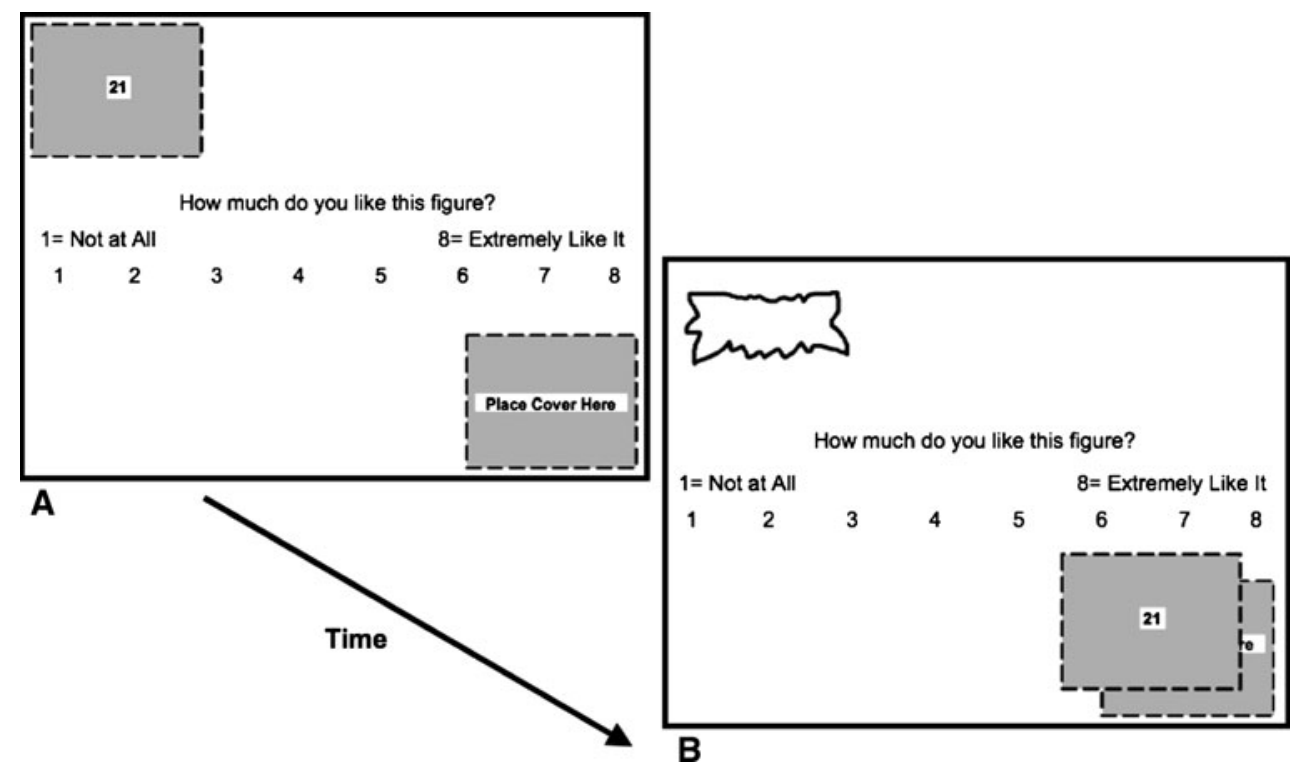


each trial the figure to be rated was occluded by the image of a square (Fig. 1a). Participants were instructed to drag the occluding square away from the figure, moving the square diagonally from the top left corner of the screen to the bottom right corner (Fig. 1b). This action revealed the image of the figure to be rated. Participants then rated how much they liked the figure on a 1-8 scale, in which 1 signified "Not at all," and 8 signified "Extremely like it." All stimuli were presented in Microsoft Power Point. The nonsense figures came from a previous study (Morsella and Bargh 2007); they were selected because they do not resemble any objects from everyday life.

Participants were run individually in a booth equipped with a computer and a booklet in which participants jotted their ratings. To match the figures to the recorded ratings, ratings were jotted down next to a number that corresponded to the number presented on the square on the screen. Participants never saw the same image twice. In this within-subjects design, order of condition and pairings of figures in the two conditions were fully counter-balanced across participants. Across participants, each figure was presented in each condition (Easy and Effortful) an equal number of times. To eradicate any stimulus order-ofpresentation effects, stimuli were presented in four pseudorandom ordered sequences. Two of the sequences presented the stimuli in the reverse order of the other two of the sequences.

Effort was manipulated by varying the fluidity with which participants could operate the computer mouse. The tracking speed of the mouse cursor was adjusted by the experimenter, using Hotkey gPhotoShow (2008) software. The software enabled the experimenter to switch quickly between the two custom mouse settings. To change the settings discreetly and direct participants' attention away from the experimenter, while changing the settings the experimenter asked participants to confirm their subjectpool number. In the Easy condition, the mouse moved at standard speed; in the Effortful condition, it was set to the slowest tracking speed. If during the session participants ever asked about the faulty computer mouse, they were told to continue the session and to reserve all questions until the end of the session. After the session, participants completed a funneled debriefing questionnaire designed to probe for suspiciousness about the purpose of the study (following the procedures of Bargh and Chartrand 2000). Specifically, participants were asked What do you think the purpose of this experiment was?, What do you think this experiment was trying to study?, Did the task require any effort?, Do you recall in which circumstances it did require effort?, and What did you usually base your liking judgments on? Importantly, although each participant reported more frustration for Effortful than Easy conditions, none inferred the hypothesis being tested.

\section{Results and discussion}

The data from three participants were excluded from analysis because one participant used the keyboard instead of the computer mouse; one changed the mouse settings; and one participant jotted down ratings for only one condition. As predicted, mean liking of nonsense images was lower for Effortful $(M=3.34$, SEM $=0.14)$ than for Easy conditions $(M=3.52, \quad \mathrm{SEM}=0.15)$, $t(43)=2.219, \quad p<0.05\left(\eta_{p}^{2}=0.10\right)$. The size of the effect $\left(\eta_{p}^{2}=0.10\right)$, and variability in the Effortful condition $(\mathrm{SD}=0.93)$, may reflect the fact that not all participants responded in the same manner to the Effortful condition: there was some evidence supporting the hypothesis that some of the participants may have generated a positive valence from the expenditure of effort. This raises the interesting question of whether individual differences (e.g., need for cognition; Cacioppo and Petty 1982) may account for a meaningful part of responsiveness to more effortful versus less effortful action. Furthermore, such a pattern may support a view that effortful goal related action can produce positive affect and approach motivation (cf. Brehm and Self 1989). Because this study was not designed to elicit positive valence from those people who may have a positive disposition toward the expenditure of effort, we leave this issue to future investigations. Nevertheless, the overall pattern of results suggests that excessively effortful action negatively colors people's subsequent judgments, and that this negative valence spills over into the evaluation of ambient stimuli. This finding complements the perceptual fluency literature (Alter and Oppenheimer 2009) by demonstrating that effortful action processing also results in negative evaluation.

To our knowledge, this is the first demonstration of negative valence resulting from a simple yet effortful action. However, a number of questions remain. First, were negative evaluations of the ambient figures due solely to the needless effort involved in moving the mouse in the Effortful condition, or did participants experience frustration (on a conscious or nonconscious level; see Chartrand 2005)? Second, when participants experienced the Effortful condition, could their violated expectations of ease of action have contributed to their negative evaluation of the ambient figures (again, instead of a pure effect of action)? Third, is overt action necessary to produce the observed valence effect, or can covert mental actions also influence the evaluation of ambient stimuli? To answer these questions and shed further light on the nature of the valence from effort effect, we examined whether covert mental actions (e.g., mentally rotating an object) can negatively color evaluations in an unintended fashion. 


\section{Study 2}

Study 1 found negative valence effects from overt, physical action, but do similar effects arise from covert, mental actions, actions that are not associated with implicating response suppression, physical exertion, expectations violation, or other aversive processes? Mental rotation is a cognitive task involving a minimal amount of effortful cognitive control, without implicating these secondary effects (Morsella et al. 2009a). Hence, it is well suited for studying the boundary conditions for the affective consequences of cognitive effort. Based on mental rotation paradigms (Shepard and Metzler 1971), participants in our study had to determine whether two nonsense shapes were different objects or the same object in a different orientation (Fig. 2), a task eliciting mental rotation. Such a determination sometimes involved more effortful $\left(135^{\circ}\right)$ or less effortful $\left(45^{\circ}\right)$ mental rotation. As in the original mental rotation studies, participants were never instructed to rotate the objects. They were only asked if the two shapes were the same or different. Thus, we would expect no differential feelings of frustration across experimental conditions, as the more or less effortful rotations only differ in terms of the amount of processing. We hypothesized that nonsense shapes associated with more effortful processing ( $135^{\circ}$ of mental rotation) would be liked less than shapes associated with easier processing ( $45^{\circ}$ of rotation).

\section{Methods}

Participants

Undergraduate students $(n=42)$ participated in a withinsubjects design for partial course credit.

\section{Procedures}

Stimuli (falling within $7 \mathrm{~cm}^{2}$; Fig. 2) were presented on a white background of an Apple iMac computer monitor with a viewing distance of approximately $48 \mathrm{~cm}$. Stimulus presentation was controlled by PsyScope software (Cohen et al. 1993). Task instructions did not mention mental rotation. Participants were told, "Your task is to determine
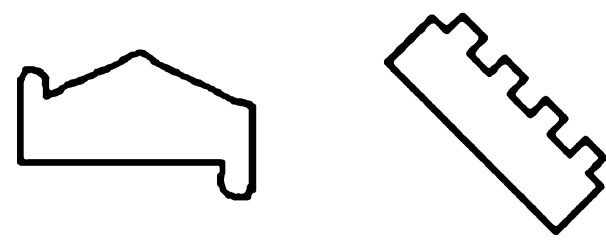

Fig. 2 Sample stimuli used in the mental rotation task whether the two objects are the same or different. Please respond as quickly as possible by pressing the ' $\mathrm{S}$ ' key if the objects are the same (identical), or the ' $\mathrm{D}$ ' key if the objects are different."

Following the presentation of a sample "Same" and "Different" trial, participants began the test trials $(n=64)$ in which, following each same/different judgment, the shape reappeared in the center of the screen (in the orientation in which it had appeared on the left-side of the screen during the same/different task), and participants were asked "How much do you like this object?" which they rated on an 8-point scale, in which 1 signified "not at all" and 8 signified "extremely like it." Critical trials $(n=32)$ showed the same object (i.e., all "Same" trials) twice, with the object on the right rotated clockwise $45^{\circ}$ (Easy Condition) or $135^{\circ}$ (Effortful Condition). For the effortful condition, we did not select the most extreme angular displacement $\left(180^{\circ}\right)$ because it would involve having one object be the 'upside down' version of the other, a transformation that, unlike that of $135^{\circ}$, may have peculiar psychological properties that could introduce artifactual effects. For example, the upside-down versions of a symbol may in-and-of-itself connote something negative (Jung 1964), as is obvious in the images of inverted flags, hearts, or religious icons. In designing the experiment, we concluded that such a possibility could introduce a confound. Second, having the object rotated on $180^{\circ}$ keeps the object in the same vertical axis, which may lead participants to attempt various strategies other than mental rotation for carrying out the task. In synthesis, because we wanted both conditions to be identical except for the amount of rotation (and effort), we decided against presenting images rotated $180^{\circ}$ in the effortful condition, an angular displacement that might have introduced more than just a greater degree of rotation (and effort).

The pairing of stimuli to condition was fully counterbalanced across participants, such that the shape that appeared in the Easy condition for one participant appeared in the Effortful condition for another participant. Due to a programming error, regarding the critical trials, half of the participants were presented with 17 Easy trials and 15 Effortful trials, and the other half were presented with 15 Easy trials and 17 Effortful trials. There was no meaningful difference in any of the reported metrics based on this difference between groups (all $F \mathrm{~s}<1$ ), and the data were collapsed. Filler trials $(n=32)$ were identical except that they presented two distinct shapes. After the trials, participants completed the funneled debriefing questionnaire from Study 1 (Bargh and Chartrand 2000). Funneled debriefing revealed that only one participant indicated some awareness of the purpose of the study; the same pattern of results is obtained with or without this participant's data. 


\section{Results and discussion}

Consistent with the results of Study 1, participants reported less liking for nonsense shapes when they were associated with more mental rotation (Effortful condition $M=4.45$, SEM $=0.18$ ) than with less mental rotation (Easy condition $M=4.60, \mathrm{SEM}=0.20), t(41)=2.394, p=0.02$, $\eta_{p}^{2}=0.12$ ). Participant typing errors resulted in the loss of $115(8.6 \%)$ out of 1,344 ratings. As in previous mental rotation studies, response times (ms) were longer for the Effortful $(M=4616.43, \quad \mathrm{SEM}=223.98)$ than Easy trials $(M=4375.43, \mathrm{SEM}=225.54), t(41)=-2.596$, $p=0.01$. As in Study 1, and potentially explained by effects stemming from individual differences or the appetitive nature of difficult goal pursuit (Cacioppo and Petty 1982; Brehm and Self 1989); see "General discussion"), the effect size $\left(\eta_{p}^{2}=0.12\right)$ may reflect individual differences regarding responses to effortful processing. Same/different error rates were comparable between conditions $\quad\left(M_{\text {Easy }}=0.09, \quad \mathrm{SEM}=0.02 ; \quad M_{\text {Effortful }}=0.08\right.$, SEM $=0.01), t(41)=0.198, p=0.84$, suggesting that valence did not stem from response accuracy. Even when collapsing across the Easy and Effortful conditions, we found no correlation between RT and likeability ratings, $r=-0.08, p>0.05$. This null correlational effect may be due in part to a restriction of the range in RT caused by their being only two rotation conditions, one limitation of this study.

These findings suggest that in an executive task involving covert action and occurring at the lower-boundary of cognitively effortful experiences, greater effort leads to negative affect. Building upon Study 1, these results lend support to the hypothesis that on the most basic level, greater effort is associated with negative affect, which is capable of coloring people's subsequent evaluations. These results speak against an interpretation that violated expectations produced the negative affect observed herein (cf., MacDowell and Mandler 1989), as the Easy and Effortful conditions differed only in terms of the amount of mental rotation necessary to complete the task, for which no a priori expectations existed within participants.

\section{General discussion}

As predicted by the valence from effort hypothesis (Botvinick 2007; Hull 1943; Lewin 1935), in Study 1 participants liked ambient figures less when using a 'slow' computer mouse requiring a greater expenditure of effort than when using a normal computer mouse. Similarly, in Study 2 we demonstrated that, in a task involving a minimal amount of effortful cognitive control, participants liked stimuli associated with effortful processing $\left(135^{\circ}\right.$ of mental rotation) less than those associated with easier processing ( $45^{\circ}$ of mental rotation). To our knowledge, this is the first demonstration of the affective consequences of mental effort, resulting not from processing fluency but instead from the exercise of a basic form of cognitive control. Together, these effects illuminate a simple mechanism-valence from effort-that may be one of many sources of avoidance motivation giving rise to the behavioral and decision-making patterns captured by the law of least effort, a law that predicts so much of human behavior.

In both studies, the valence effect could not be attributed to the peculiarities of the figures, because each figure was presented an equal number of times in both the easy and effortful conditions. In this way, any valence effects stemming from the stimuli themselves should have been aggregated away. Our counterbalancing method also controlled for both stimulus-order and block-order effects. Importantly, no participant reported explicit understanding of the hypothesis being tested, suggesting that the effects were not artifacts arising from experimental demand.

\section{Limitations of the approach}

One limitation of Study 1 is that our paradigm cannot pinpoint which aspect(s) of action implementation is primarily responsible for valence effects. For example, valence may arise from the online and continuous effort involved in action execution/correction, impatience at the rate of progress by which the square moves across the screen as function of each drag, or, more globally, from the inability to quickly reach a goal state (having the square positioned at the bottom right corner of the screen). For example, it could be that a negative valence in Study 1 arose from perception of the malfunctioning computer mouse. Similarly, in Study 2 , valence may have been influenced by the relative 'feelings of success,' which would be different for the two conditions. More likely, the effect could have stemmed from a combination of these factors. Nevertheless, at this stage of understanding, we propose that it is the valence from effort hypothesis that most parsimoniously accounts for the findings of the two dissimilar tasks.

Future research may home in on the aspect(s) that are most responsible for valence effects in this kind of scenario. In both studies, the degree to which the nonsense figure could be deemed to be 'incidental' remains unclear. Do similar effects valence effects spill-over to objects that are even more incidental? This question will have to be addressed by future research involving target stimuli that are less focal. One limitation of Study 2 is that only two rotation conditions were used, thereby limiting statistical analyses that could reveal a linear relationship between RT and likeability. Studies 1 and 2 were designed to test in a statistically powerful manner the prediction that the kinds 
of fluency effects obtained with perceptuo-semantic processing occur for processes involving action and executive control. Future studies should be designed to reveal more nuanced effects, for example, by having more gradations in the levels of the experimental factor examined in Study 2. It is important to note that the goal in this project was to demonstrate that effortful, action-related processing can create a negative valence that then influences likeability of neutral, ambient stimuli. More theoretically, these data do not directly support the claim that, in future action selection, valence acquired in this way will create avoidance dispositions toward the tasks and stimuli that had been associated with the effortful processing. Such a demonstration is left for future investigations.

As a predictor of behavior, one limitation of the law of least effort is that organisms often do seek activities that, though associated with the expenditure of energy, furnish little, if any, energy as a payoff. In a cost-benefit analysis, these activities seem energy inefficient, at least at first glance. For instance, Harlow et al. (1950) found that animals will lever press (an effortful act) to simply witness a change in illumination. It is obvious that in humans, energy-consuming activities are sought even when all the needs of the organism are sated. This stimulation is sought to counteract the negative affect associated with suboptimal arousal or 'boredom' (Berlyne 1960). The ethologists have characterized these stimulation-seeking behaviors as resulting from adaptive 'exploratory drives' (Thorpe 1964), which can lead to a form of latent learning (Tolman and Honzik 1930) that does have survival value for the organism in the long run. Thus, the relationship between valence and effort/conflict is probably more complicated than that portrayed by traditional accounts (e.g., the law of least effort; Botvinick 2007; Hull 1943). There are other reasons for suspecting that effort does not always produce negative feelings. For example, the experience of 'flow,' the subjective experience of being completely immersed in effortful cognitive or physical activity, is experienced pleasantly (Csikszentmihalyi et al. 2005). Furthermore, individuals high in a need for cognition express more positive attitudes towards complex mental tasks, compared to simple, less effortful tasks (Cacioppo and Petty 1982).

To explain such positive-valence from effort findings, others have appealed to the homeostatic notion that the cognitive apparatus strives to maintain an optimal level of arousal (Kahneman 1973; see also the classic work by Berlyne 1960). When below this threshold, arousal is increased by engaging in activities such as fiddling with objects or body parts (Morsella et al. 2010). ${ }^{1}$ More

\footnotetext{
${ }^{1}$ For an account regarding how these task-irrelevant activities can actually facilitate certain cognitive tasks, see Olivers and Nieuwenhuis (2005).
}

specifically, effort-related valence effects often depend on background levels of neural 'activation' (Sanders 1983) and homeostatic mechanisms concerned with optimal levels of arousal (Berlyne 1960; Berlyne 1972; Morsella et al. 2009a; Kahneman 1973). For instance, in the midst of an unchallenging, monotonous task (the kind of task commonly encountered in the psychology laboratory), participants may actually welcome cognitive conflict/interference (Berlyne 1960; Berlyne 1970; Berlyne 1972; Kahneman 1973; Morsella et al. 2010; Riddle et al. 2009; Sanders 1983). For instance, some data suggest that, as time at task increases, participants tend to dislike response interference less and less (Riddle et al. 2009).

Furthermore, on the surface, the effects reported herein also appear to conflict with the long line of research on motivational intensity theory (Brehm et al. 1983; Brehm and Self 1989; Wright 1996). A consistent finding in this line of research is that goals become more, not less, appetitive (and more intensely pursued) as the amount of effort needed to achieve them increases. For example, when given a free choice between food that was consistently easier versus more difficult to obtain, rats show a preference for the difficult-to-obtain food, suggesting that more, not less, effort increased the attractiveness of the goal (Friedman et al. 1968). Empirical findings such as these led to the conclusion that, "[m]otivational arousal rises with increasing difficulty of instrumental behavior up to the point where the required effort is greater than justified by the motive" (Brehm and Self 1989, p. 129). Thus, one might suspect that effortful action would be associated with positive affect, an important precursor for goal pursuit (Aspinwall 1998; Custers and Aarts 2005). However, a consideration of the nature of the affective outcomes associated with effortful action suggests that Brehm's energization theory can be reconciled with our present analysis. Whereas motivational intensity theory deals primarily with the consequences of task effort on goal valence, we explore the affective consequences of effortful action on the evaluation of incidental stimuli and secondary outcomes that are not goals in themselves, but rather are associated with the effortful (overt and covert) actions themselves (i.e., means). In our paradigm, the shapes to-berated were incidental and never constituted the goal: In Study 1, the goal was to move the square diagonally from the top left corner of the computer screen to the bottom right corner; in Study 2, the goal was to determine whether the two visual stimuli were the same or different. Thus, although effortful action may be associated with increased goal pursuit (and enhanced desirability of end-states; cf. Biner et al. 1991), such effort may also be capable of producing ancillary negative emotions, which can influence future action selection by decreasing liking for ambient stimuli and secondary outcomes linked to the effortful 
action (present analysis). In short, action difficulty may be simultaneously energizing (leading to positive valence toward the goal) and capable of instilling negative valence toward incidental stimuli, which may then influence which means are selected to reach the goal in the future.

Substantial research will be required to determine whether apparent violations of the law of least effort result from the homeostatic nature of the brain or, more specifically, from exploratory drives that, though energy inefficient at one moment in time, may be adaptive in the long run. In either case, the need to conserve energy must always influence processing to some extent. Valence from effort may instantiate such an influence. The (positive) motivational consequences of effort may signal to the organism that a goal is worth pursuing, whereas the (negative) affective consequences of effort may signal to the organism when it is appropriate to abandon and cease goal pursuit. Supporting this notion, recent work has found that engendering a temporary implicit association between negative affect and a goal leads to the cessation of the nonconscious pursuit of that goal (Aarts et al. 2007).

\section{Implications and future directions}

Knowing when minimal mental effort will engender negative affect can be an important tool for cognitive-behavioral treatments of neurological conditions such as multiple sclerosis, in which depressed mood often plays a role (Diamond et al. 2008). Furthermore, in educational and workplace contexts, these results highlight the challenges instructors and employers face, as the experience of negative affect can be a motivational hurdle (Carver et al. 1983; Dweck and Leggett 1988). Introducing appetitive stimuli into these contexts rich with self-regulatory challenges may help overcome the negative affect produced by cognitive effort (cf., Fredrickson and Losada 2005).

More generally, it remains unknown why the brain, as an affinity-based system (Chomsky 1988), comes to prefer processing dynamics over others (Bindra 1959; Morsella 2005). It seems that metabolic processes (e.g., glucose consumption) are too slow to be responsible for the changes in subjective experience (e.g., Sherrington's sense of effort; cf., Jeannerod 2006) that are associated with the kinds of effortful situations that lead to valence effects. It is our hope that our basic finding may spur investigations that explain the neural underpinnings of the sense of effort and its intimate relationship to valence. According to Botvinick (2007), it is the anterior cingulate cortex that is responsible for detecting this kind of 'inefficient processing' that an organism should later avoid. Together with this kind of framework, and because so much is known about the neural correlates of mental rotation (Gauthier et al. 2002), the paradigm introduced in Study 2 may illuminate pathological conditions. Such investigations may shed light on conditions involving subjective fatigue, cognitive effort, and negative valence (e.g., multiple sclerosis; Bailey et al. 1995).

Lastly, with respect to motivational intensity theory, it may be interesting to ascertain whether goal energization effects are simultaneously associated with greater liking of difficult-to-achieve goals (compared to easy-to-achieve goals) and less liking of the effortful actions needed to achieve those goals (compared to easy actions). Biner et al. (1991) demonstrated that hungry participants valued a cheeseburger more when successful completion of an effortful (vs. easy) task was necessary to obtain it. Even though participants evaluated the difficulty of the memory task, participants did not report whether they liked the difficult memory task less than the easy task, which we would predict based on the present findings. Future research can better specify the affective consequences of difficult actions for evaluating means versus ends.

In summary, these two investigations suggest that at the low extremes of physical and mental effort, needless, excessive effort is associated with negative affect, standing in contrast to other theoretical perspectives in which a high degree of mental effort produces pleasant subjective experiences (e.g., flow; Csikszentmihalyi et al. 2005). Given these findings, a more complete picture of the affective consequences of mental effort emerges. Future research can further examine the relationship between cognitive effort and affect, by isolating the components of the effortful experiences. For example, physiological arousal may meaningfully contribute to the positive experience of effort at the upper boundary (cf., Berlyne 1960), and when arousal is low, effort may induce positive affect (cf., Kahneman 1973; Sanders 1983). On the most basic level, however, it appears that the needless expenditure of energy produces negative feelings.

Acknowledgments We gratefully acknowledge the assistance of Stephen Krieger and Chuck Tate.

Open Access This article is distributed under the terms of the Creative Commons Attribution Noncommercial License which permits any noncommercial use, distribution, and reproduction in any medium, provided the original author(s) and source are credited.

\section{References}

Aarts, H., Custers, R., \& Holland, R. W. (2007). The nonconscious cessation of goal pursuit: When goals and negative affect are coactivated. Journal of Personality and Social Psychology, 92, $165-178$.

Alter, A. L., \& Oppenheimer, D. M. (2006). Predicting short-term stock fluctuations by using processing fluency. Proceedings of the Natural Academy of Sciences, 103, 9369-9372. 
Alter, A. L., \& Oppenheimer, D. M. (2009). Uniting the tribes of fluency to form a metacognitive nation. Personality and Social Psychology Review, 13, 219-235.

Arkin, R. C. (1998). Behavior-based robotics. Cambridge, MA: The MIT Press.

Aspinwall, L. G. (1998). Rethinking the role of positive affect in selfregulation. Motivation and Cognition, 22, 1-32.

Bailey, A., Channon, S., \& Beaumont, J. G. (1995). The relationship between subjective fatigue and cognitive fatigue in advanced multiple sclerosis. Multiple Sclerosis, 13, 73-80.

Bargh, J. A., \& Chartrand, T. L. (2000). The mind in the middle: A practical guide to priming and automaticity research. In H. T. Reis \& C. M. Judd (Eds.), Handbook of research methods in social and personality psychology (pp. 253-285). United Kingdom: Cambridge University Press.

Bargh, J. A., \& Morsella, E. (2008). The unconscious mind. Perspectives on Psychological Science, 3, 73-79.

Beilock, S. L., \& Holt, L. E. (2007). Embodied preference judgments: Can likeability be driven by the motor system? Psychological Science, 18, 51-57.

Berlyne, D. E. (1960). Conflict, arousal, and curiosity. New York: McGraw Hill.

Berlyne, D. E. (1970). Novelty, complexity, and hedonic value. Perception \& Psychophysics, 8, 279-286.

Berlyne, D. E. (1972). Reinforcement values of visual patterns compared through concurrent performances. Journal of the Experimental Analysis of Behavior, 18, 281-285.

Bindra, D. (1959). Motivation. New York: Ronald Press Co.

Biner, P. M., Hua, D. M., Kidd, H. J., \& Spencer, P. M. (1991). Incentive strength, need state, instrumental task difficulty, and the magnitude of goal valence. Personality and Social Psychology Bulletin, 17, 442-448.

Botvinick, M. (2007). Conflict monitoring and decision making: Reconciling two perspectives on anterior cingulate function. Cognitive, Affective and Behavioral Neuroscience, 7, 356-366.

Brehm, J. W., \& Self, E. A. (1989). The intensity of motivation. Annual Review of Psychology, 40, 109-131.

Brehm, J. W., Wright, R. A., Solomon, S., Silka, L., \& Greenberg, J. (1983). Perceived difficulty, energization, and the magnitude of goal valence. Journal of Experimental Social Psychology, 19, $21-48$.

Cacioppo, J. T., \& Petty, R. E. (1982). The need for cognition. Journal of Personality and Social Psychology, 42, 116-131.

Carver, C. S., Peterson, L. M., Follansbee, D. J., \& Scheier, M. F. (1983). Effects of self-directed attention on performance and persistence among persons high and low in test anxiety. Cognitive Therapy and Research, 7, 333-354.

Chartrand, T. L. (2005). Mystery moods and perplexing performance: Consequences of succeeding and failing at a nonconscious goal. Unpublished manuscript, Duke University.

Chomsky, N. (1988). Language and problems of knowledge: The Managua lectures. Cambridge, MA: MIT Press.

Cohen, J. D., Dunbar, K., \& McClelland, J. L. (1990). On the control of automatic processes: A parallel distributed processing account of the Stroop effect. Psychological Review, 97, 332-361.

Cohen, J. D., MacWhinney, B., Flatt, M., \& Provost, J. (1993). PsyScope: A new graphic interactive environment for designing psychology experiments. Behavior Research Methods, Instruments, \& Computers, 25, 257-271.

Csikszentmihalyi, M., Abuhamdeh, S., \& Nakamura, J. (2005). Flow. In A. J. Elliot \& C. S. Dweck (Eds.), Handbook of competence and motivation (pp. 598-608). New York: Guilford.

Custers, R., \& Aarts, H. (2005). Positive affect as implicit motivator: On the nonconscious operation of behavioral goals. Journal of Personality and Social Psychology, 89, 129-142.
DeSoto, M. C., Fabiani, M., Geary, D. C., \& Gratton, G. (2001). When in doubt, do it both ways: Brain evidence of the simultaneous activation of conflicting responses in a spatial Stroop task. Journal of Cognitive Neuroscience, 13, 523-536.

Diamond, B. J., Johnson, S. K., Kaufman, M., \& Graves, L. (2008). Relationships between information processing, depression, fatigue and cognition in multiple sclerosis. Archives of Clinical Neuropsychology, 23, 189-199.

Dweck, C. S., \& Leggett, E. L. (1988). A social-cognitive approach to motivation and personality. Psychological Review, 95, 256-273.

Fenske, M. J., \& Raymond, J. E. (2006). Emotional influences of selective attention. Current Directions in Psychological Science, $15,312-316$.

Fredrickson, B. L., \& Losada, M. (2005). Positive affect and the complex dynamics of human flourishing. American Psychologist, 60, 678-686.

Friedman, H., Tarpy, R. M., \& Kamelski, P. (1968). The preference of rats for a more difficult task. Psychonomic Science, 13, 157-158.

Garbarino, E., \& Edell, J. (1997). Cognitive effort, affect, and choice. Journal of Consumer Research, 24, 147-158.

Gauthier, I., Hayward, W. G., Tarr, M. J., Anderson, A. W., Skudlarski, P., \& Gore, J. C. (2002). BOLD activity during mental rotation and viewpoint-dependent object recognition. Neuron, 34, 161-171.

Gollwitzer, P. M., Parks-Stamm, E. J., \& Oettingen, G. (2009). Living on the edge: Shifting between nonconscious and conscious goal pursuit. In E. Morsella, J. A. Bargh, \& P. M. Gollwitzer (Eds.), Oxford handbook of human action (pp. 603-624). New York: Oxford University Press.

gPhotoShow. (2008). Mouse speed switcher (Version 1.2). [Computer Software]. http://www.gphotoshow.com.

Harlow, H. F., Harlow, M. K., \& Meyer, D. R. (1950). Learning motivated by a manipulation drive. Journal of Experimental Psychology, 40, 228-235.

Higgins, E. T. (1987). Self-discrepancy: A theory relating self and affect. Psychological Review, 94, 319-340.

Higgins, E. T. (2005). Value from regulatory fit. Current Directions in Psychological Science, 14, 209-213.

Hull, C. L. (1943). Principles of behavior. New York: AppletonCentury.

Jacoby, L. L., Kelley, C. M., \& Dywan, J. (1989). Memory attributions. In H. L. Roediger \& F. M. Craik (Eds.), Varieties of memory and consciousness: Essays in honor of Endel Tulving (pp. 391-422). Hillsdale, NJ: Erlbaum.

Janiszewski, C., \& Meyvis, T. (2001). Effects of brand logo complexity, repetition, and spacing on processing fluency and judgment. Journal of consumer research, 28, 18-32.

Jeannerod, M. (2006). Motor cognition: What action tells the self. New York: Oxford University Press.

Jung, C. G. (1964). Man and his symbols. New York: Dell Publishing Company.

Kahneman, D. (1973). Attention and effort. Englewood Cliffs, NJ: Prentice Hall.

Kruglanski, A. W., \& Kopetz, C. (2009). The role of goal systems in self-regulation. In E. Morsella, J. A. Bargh, \& P. M. Gollwitzer (Eds.), Oxford handbook of human action (pp. 350-367). New York: Oxford University Press.

Lewin, K. (1935). A dynamic theory of personality. New York: McGraw-Hill.

Luce, M. (1998). Choosing to avoid: Coping with negative emotionladen consumer decisions. Journal of Consumer Research, 24, 409-433.

Luce, M., Bettman, J., \& Payne, J. (1997). Choice processing in emotionally difficult decisions. Journal of Experimental Psychology. Learning, Memory, and Cognition, 23, 384-405. 
MacDowell, K. A., \& Mandler, G. (1989). Constructions of emotion: Discrepancy, arousal, and mood. Motivation and Emotion, 13, $105-124$.

MacLeod, C. M., \& McDonald, P. A. (2000). Interdimensional interference in the Stroop effect: Uncovering the cognitive and neural anatomy of attention. Trends in Cognitive Sciences, 4, 383-391.

Morsella, E. (2005). The function of phenomenal states: Supramodular interaction theory. Psychological Review, 112, 1000-1021.

Morsella, E. (2009). The mechanisms of human action: Introduction and background. In E. Morsella, J. A. Bargh, \& P. M. Gollwitzer (Eds.), Oxford handbook of human action (pp. 1-32). New York: Oxford University Press.

Morsella, E., \& Bargh, J. A. (2007). Valence from conflict. Unpublished manuscript, Yale University.

Morsella, E., \& Bargh, J. A. (in press). Unconscious action tendencies: Sources of 'un-integrated' action. In J. Decety and J. Cacioppo (Eds.), Oxford handbook of social neuroscience. New York: Oxford University Press.

Morsella, E., Gray, J. R., Krieger, S. C., \& Bargh, J. A. (2009a). The essence of conscious conflict: Subjective effects of sustaining incompatible intentions. Emotion, 9, 717-728.

Morsella, E., Larson, L. R. L., \& Bargh, J. A. (2010). Indirect cognitive control, working-memory-related movements, and sources of automatisms. In E. Morsella (Ed.), Expressing oneself / expressing one's self: Communication, cognition, language, and identity (pp. 61-90). London, UK: Taylor and Francis.

Morsella, E., Wilson, L. E., Berger, C. C., Honhongva, M., Gazzaley, A., \& Bargh, J. A. (2009b). Subjective aspects of cognitive control at different stages of processing. Attention, Perception, and Psychophysics, 71, 1807-1824.

Olivers, C. N. L., \& Nieuwenhuis, S. (2005). The beneficial effect of concurrent task-irrelevant mental activity on temporal attention. Psychological Science, 16, 265-269.

Oppenheimer, D. M. (2006). Consequences of erudite vernacular utilized irrespective of necessity: Problems with using long words needlessly. Applied Cognitive Psychology, 20, 139-156.

Oppenheimer, D. M. (2008). The secret life of fluency. Trends in Cognitive Sciences, 12, 237-241.

Reber, R., Winkielman, P., \& Schwarz, N. (1998). Effects of perceptual fluency on affective judgments. Psychological Science, 9, 46-48.
Riddle, T. A., Lynn, M. T., \& Morsella, E. (2009). The phenomenology of quitting: Effects from repetition and cognitive conflict. (Unpublished manuscript).

Rosen, Z. V., McGuire, J., \& Botvinick, M. M. (2007). Is mental effort aversive? Some behavioral and psychophysiological evidence. Paper presented at the Cognitive Neuroscience Society Annual Meeting.

Rosenbaum, D. A. (2005). The Cinderella of psychology: The neglect of motor control in the science of mental life and behavior. American Psychologist, 60, 308-317.

Sanders, A. F. (1983). Towards a model of stress and human performance. Acta Psychologica, 53, 61-97.

Schacter, D. L., \& Addis, D. R. (2007). The cognitive neuroscience of constructive memory: Remembering the past and imagining the future. Philosophical Transactions of the Royal Society of London. Series B, Biological Sciences, 362, 773-786.

Schwarz, N. (2004). Metacognitive experiences in consumer judgment and decision making. Journal of Consumer Psychology, 14, 332-348.

Shepard, R., \& Metzler, J. (1971). Mental rotation of three dimensional objects. Science, 171, 701-703.

Thorpe, W. H. (1964). Learning and instinct in animals. Cambridge, MA: Harvard University Press.

Tolman, E. C., \& Honzik, C. H. (1930). Introduction and removal of reward, and maze performance in rats. University of California Publications in Psychology, 4, 257-275.

Vygotsky, L. S. (1962). Thought and language. Cambridge, MA: The MIT Press.

Winkielman, P., Schwarz, N., Fazendeiro, T., \& Reber, R. (2003). The hedonic marking of processing fluency: Implications for evaluative judgment. In J. Musch \& K. C. Klauer (Eds.), The psychology of evaluation: Affective processes in cognition and emotion (pp. 189-217). Mahwah, NJ: Lawrence Erlbaum.

Wright, R. A. (1996). Brehm's theory of motivation as a model of effort and cardiovascular response. In P. M. Gollwitzer \& J. A. Bargh (Eds.), The psychology of action: Linking cognition and motivation to behavior (pp. 424-453). New York: Guilford. 